\title{
Interactive Component in Oral \\ Narratives of Preschool Children: \\ on the Formulation of Hypothesis
}

\section{Интерактивный компонент в устных нарративах детей-дошкольников: \\ к постановке гипотезы}

Nadezhda Yurieva

Doctor in Philology,

Senior Researcher
Надежда Юрьева

доктор филологических наук, ведущий научный сотрудник

E-mail: o.yuriev@list.ru

orcid.org/0000-0001-8537-1713

Institute of linguistics of Russian Academy of Sciences, Department of

Experimental Studies of Speech

1/1, B. Kislovskiy Per., Moscow, Russia, 125009
Институт языкознания РАН, отдел экспериментальных исследований речи

$\square$ Большой Кисловский пер., д. 1/1, Москва, Россия, 125009

Original manuscript received July 19, 2018

Revised manuscript accepted February 18, 2019

\begin{abstract}
The article presents an effort to elaborate the hypothesis for the experimental research devoted to interactive component in the oral narratives of preschool children. It is vital for psycholinguistics to reach a close approach to understanding of the essence of narrative processes which have in ontogenesis their own specifics, and according to some researches, these specifics are presented in indirect character of the process of narrative creation by child in the form of his verbal interaction with an adult.

We assume that in order to reveal the ontogenetic cognitive discursive mechanisms involved in the process of narration, it is necessary to correlate the


regularities of the verbal interaction of the participants in the narrative situation with the overall narrative tasks coming up in narrative process.

Methodology, purpose and tasks of the research are determined by experimentally-genetic method (L.S. Vygotsky) put forward as main requirements "differentiation of the analysis of a thing and analysis of the process", "genetic restoration of all moments of the process development». The following of these requirements means a close following of the process of narrative development in its dynamics and the peculiarities of its formation at different stages of child's development, paying attention to frequency facts as well as facts overcoming the limits of "narrow» phenomenon - narrative text.

To work out the hypothesis the narrative material of the earlier made experiment with a group of 3 to 7 age children was used in which an adult took a passive part. The task was to tell the story. The material was not subjected to any analysis for the reason of the adult's presence during the storytelling. The analysis of oral histories with interactive component included the following tasks: a) choose regular sequences of utterances in the dialogic interaction of child and adult; b) define the functional purpose of the adult's utterance in the course in the child's storytelling.

The obtained results show that the adult practically at every step of the child's age is oriented on the child's comprehension and analyzing episodes of the history, that is on child's formation of his mental image of structural and event sequence in history. The results of the analysis enabled us to propose a hypothesis for the next research step in the field. Along the line of this hypothesis, in the verbal ontogenesis the very nature of oral story as a multifaceted phenomenon of the discursive activity of man brings up to the surface the inner mechanisms of narration which have dialogue basis.

Key words: oral narrative, narrative development, interactive component, genesis of oral narrative, dialogue basis.

\section{Вступление}

На протяжении нескольких последних десятилетий психолингвистика речевого онтогенеза характеризуется обращением к комплексу проблем, связанных с коммуникативной компетенцией, особенностями ее становления в онтогенезе и разнообразными дискурсивными феноменами, в которых проявляется языковая личность в ее способности к речевой коммуникации и взаимодействию с окружающим миром (Седов, 2004). Коммуникативная компетенция традиционно в большей мере связывается с разговорной речью и диалогом, чем с монологической 
речью и такой протяженной дискурсивной формой, как нарратив или повествование. Наблюдения за особенностями освоения родного языка ребенком показывают, что в речевом онтогенезе устный нарратив оказывается «затерянным» в диалогическом пространстве языка и речевого взаимодействия ребенка с окружающими. Именно поэтому психолингвистика речевого онтогенеза долгое время не оказывала особого внимания проблемам, связанным c возникновением явлений устного нарратива в речи детей дошкольного возраста. Формирование монологического дискурса традиционно относят к школьному курсу грамматики родного языка и к учебной дискурсивной практике. Вместе с тем маленькие дети всегда что-то рассказывают о том, что с ними произошло, что они узнали, о друзьях, семье, а взрослый, в свою очередь, охотно выслушивает их рассказы и, так или иначе, реагирует на них. Поэтому можно считать, что основы дискурсивных умений в области связного нарратива закладываются у ребенка раньше, чем в школьный период. Однако об особенностях становления нарратива в речевой деятельности человека, говоря словами Р. Барта, «мы знаем не больше, чем о происхождении языка» (Барт, 2000: 231).

Начиная с 70-х годов прошедшего столетия, для зарубежной науки характерен постоянный интерес к способности и умениям детей рассказывать, понимать и пересказывать истории. Результаты исследований свидетельствуют о важности и актуальности разработки проблем становления нарративного дискурса, одна из которых предполагает изучение механизмов речевой интеракции в генезисе нарратива в речевой деятельности ребенка. Интерактивный компонент, представленный диалогическими репликами взрослого, которые «внедряются» в процесс рассказывания ребенком истории, долгое время исключался из анализа и не рассматривался как значимый компонент нарративного процесса (Quasthoff, 1997: 51-83).

К первым отечественным онтолингвистическим работам, обращенным к повествованию в детской речи, принадлежат исследования Е.Ю. Протасовой, Н.И. Лепской и К.Ф. Седова, в которых заложена теоретико-экспериментальная основа изучения эволюции повествовательного дискурса в речи детей (Протасова, 1987; Лепская, 1997; Седов, 1999, 2004). В исследовании Е.Ю. Протасовой получены данные, свидетельствующие, 
Interactive Component in Oral Narratives of Preschool Children...

что развитие повествования у ребенка является отражением развивающейся «способности к созданию текстов-описаний», отмеченных появлением двусоставных предложений, организующих структуру текста, возникновением связи между предложениями и «логики описания: от главного к деталям». Одновременно происходит овладение ребенком культурно-исторической нормой описания картинок определенного типа, возникает оценка действий, интерпретация событий (Протасова, 1987: 17-18). В работе Н.И. Лепской выявлены особенности создания текстов-монологов детьми 4-10 лет на основе детального анализа «онтогенетически ранних текстов», возникающих в разных экспериментальных ситуациях: в результате пересказа прочитанного рассказа, в ходе самостоятельного рассказывания некоторой истории и создания рассказа по сериям картинок (Лепская, 1997: 78-86). По данным Н.И. Лепской, дети дошкольного возраста и даже первоклассники в основном справляются с пересказом текста только при опоре на наводящие вопросы экспериментатора (Лепская, 1997: 79). Еще более трудным для ребенка является самостоятельное порождение текста, поскольку оно связано с комплексом речемыслительных действий, обеспечивающих процесс порождения: формирование замысла рассказа или истории, осмысление логики развития событий и их взаимосвязи, отбор языковых средств и их упорядочивание для реализации задуманного (Лепская, 1997: 80-81). Весомый вклад в изучение эволюции дискурсивной компетенции внесли исследования К.Ф. Седова, в которых сформирована концепция, интегрирующая важнейшие направления лингвистики конца XX века: антропоцентрическое, коммуникативно-деятельностное и дискурсивное. В основе концепции лежит известная идея, что «главным средством самовыражения языковой личности выступает текст (дискурс)», позволившая автору найти многоаспектный подход к изучению структуры дискурса и эволюции дискурсивного мышления языковой личности (Седов, 1999: 3). Экспериментальный нарративный материал по возрастным срезам школьников от 6 до 16 лет воссоздает многоаспектную картину, отражающую «разные грани» дискурсивной компетенции и нарратива школьников (Седов, 2004: 276).

Основная цель большинства современных зарубежных исследований в области нарративного развития, которые 
проводятся с разных теоретических позиций, состоит в том, чтобы «открыть, как дети научаются рассказывать истории, и как эти истории изменяются с течением жизни» (Bamberg, 1997: 7-13). C возникновением когнитивно-дискурсивного направления, a также понимая, что чисто формальное рассмотрение нарративных произведений детей для раскрытия сущности нарративных процессов, разворачивающихся в онтогенезе, недостаточно, ученые обращаются к области когнитивно-дискурсивных процессов и механизмов, обеспечивающих порождение устного нарратива детьми. В этой статье мы выделяем лишь некоторые исследования, идеи и результаты, которые, по нашему мнению, являются важными для разработки гипотезы нашего экспериментального исследования.

Среди заметных направлений, разрабатывающих проблему устного нарратива детей, выделяется когнитивное направление, ориентированное на область внутренних механизмов и отдельных звеньев порождения нарратива, а также на выявление знаний и умений, необходимых ребенку для рассказывания историй. К ним авторы относят такие когнитивные умения, как умения организовать содержание и структуру эпизодов истории в когерентное целое. По мнению Н.Л. Стейн и ее соавторов, отмеченные умения обусловлены двумя самостоятельными, но взаимосвязанными звеньями когнитивного механизма: «ментальным компонентом ситуации «цель - действие - результат»» и «концептуальной репрезентацией устной истории как специфической формы дискурса» (Stein \& Albro, 1997: 5-44; Trabasso, Stein \& Rodkin, 1992; Юрьева, 2016b: 285-286).

В исследованиях Ю. Кастхофф и Н. Хаузендорф устный нарратив детей разрабатывается в русле интерактивного подхода, в своих методологических основаниях и процедурах анализа, опирающегося на конверсационный анализ и понятие интеракции, определяющее осмысление нарратива как «интерактивного целого» (Quasthoff, 1997: 51-83; Hausendorf \& Quasthoff, 1992: 241-260; Юрьева, 2018: 116-117). Внимание исследователей обращено к конверсационному нарративу, возникающему в ситуациях повседневного общения ребенка и взрослого. Авторами привлекается дискурсивный материал экспериментов с детьми предшкольного, младшего и среднего школьного возрастов. Основная задача анализа состоит в определении регулярностей речевого взаимодействия, 
Interactive Component in Oral Narratives of Preschool Children...

посредством которых участники конверсационной интеракции реализуют нарративные задачи. Показано, что конверсационный нарратив предстает в виде «повествовательных паттернов» внутри речевого взаимодействия ребенка-рассказчика и взрослого (Quasthoff, 1997: 52; Юрьева, 2017: 178-181). По данным анализа материалов «постановочного» эксперимента, воссоздающего некоторое реальное событие, произошедшее в присутствии ребенка, Ю. Кастхофф пришла к выводу, что речевая «интеракция в конверсационном нарративе активирует некоторые фрагменты знания ребенка о событии, свидетелем которого он являлся» (Quasthoff, 1997: 70; Юрьева, 2018: 120).

Основной итог исследований, проводимых в русле интерактивного подхода, позволяет осмысливать конверсационный нарратив не только как интерактивную форму устного нарратива, но и как «необходимый этап генезиса устного нарратива в речи детей» (Юрьева, 2018: 122). Следует подчеркнуть, что в исследованиях интерактивного направления представлена попытка объяснения нарративного развития ребенка и его продвижения к связному нарративу, которое проходит на базисе конверсационных отношений в нарративной ситуации с «несбалансированными коммуникативными компетенциями» участников (Quasthoff, 1997: 51-83). По словам М. Бамберга, в подобных нарративных ситуациях «оба участника являются равно важными для осуществления наррации» (Bamberg, 1997: 46).

Вместе с тем, обращаясь к интерактивной основе онтогенетических нарративных механизмов, М. Бамберг справедливо считает, что «недостаточно реконструировать структурные признаки речевой интеракции участников и, в частности, высказываний взрослого, который поддерживает нарративную активность ребенка и, таким образом, создает основу для нарративного дискурса». По его словам, «если мы не хотим связывать проблему с обычными рассуждениями о существовании врожденного лингво-обучающего механизма у взрослого, то необходимо найти девелопментально ориентированный», другими словами, онтогенетический функциональный механизм, «действующий внутри интерактивных структур» (Bamberg, 1997: 46-47).

Для современной психолингвистики важно приблизиться к пониманию сущности нарративных процессов, имеющих в 
онтогенезе свою специфику, состоящую, по данным ряда работ, в опосредованном характере создания нарратива ребенком, который представлен в форме речевого взаимодействия со взрослым. Мы полагаем, что для выявления онтогенетических когнитивнодискурсивных механизмов, вовлеченных в процесс нарративизации, необходимо соотнести имеющиеся регулярности в речевом взаимодействии участников наративной ситуации с общими нарративными задачами, возникающими перед рассказчиком для построения связного нарратива.

Далее в статье привлекается материал, полученный нами в ранее проведенном эксперименте с детьми-дошкольниками 3-7 лет по рассказыванию истории и не подвергавшийся анализу, поскольку в нем зафиксирован диалог ребенка и взрослого. Материалом данного исследования являются устные истории, включающие диалог ребенка и взрослого. На основе материалов эксперимента по рассказыванию детьми истории с пассивной формой участия взрослого предпринимается попытка подойти к формулированию гипотезы об интерактивном компоненте в генезисе устного нарратива в детской речи.

\section{Методы и методики исследования}

Цель и задачи исследования определяются экспериментальногенетическим методом, выдвигающим в качестве основных требований «различение анализа вещи и анализа процесса», «генетическое восстановление всех моментов развития данного процесса» (Выготский, 1983: 94-95; Лидерс \& Фролов, 1991: 52; Сигал \& Юрьева, 2009: 50-52). Следование этим требованиям состоит в том, чтобы проследить становление нарратива в динамике его формирования и особенностях его порождения в разные периоды развития ребенка, обращая внимание, как на частотные факты, так и на факты, выходящие за границу описываемого «узкого» феномена - нарративного текста.

Процедура эксперимента состояла в рассказывании ребенком истории о лягушке «Frog where are you?»(Mayer, 1969), представленной в иллюстрациях без вербального текста, которые, по мнению исследователей, представляют собой стандартный 
Interactive Component in Oral Narratives of Preschool Children...

материал для изучения повествований. Стимульный материал был апробирован в ряде исследований (Berman \& Slobin, 1994).

В эксперименте принимали участие русскоязычные детимонолингвы от трех до семи лет без отклонений в речевом и когнитивном развитии, посещающие детский сад г. Москвы Юго-Восточного округа, и взрослый экспериментатор, выступающий в роли слушателя и пассивного участника нарративной ситуации. Речевое и общее развитие детей специально не определялось, поскольку образовательные группы в дошкольных учреждениях не предусматривают подобных процедур и формируются по возрастному принципу. Социально-экономический статус семьи не уточнялся. Взрослый включался в нарративизацию в ответ на обращение ребенка. Перед началом сеансов ребенок и взрослый вместе рассматривали книгу, после ее просмотра взрослый просил ребенка рассказать историю, которая происходит с главным героем. Запись материала осуществлялась с помощью магнитофона, затем проводилась письменная расшифровка записей. Конверсационная активность ребенка и взрослого расписывалась по двум рядам. Основные результаты этой серии экспериментов опубликованы в работе (Сигал, Бакалова, Пушина \& Юрьева, 2013).

В этой статье используются материалы с пассивной формой участия взрослого, ранее не подвергавшиеся анализу, поскольку в рассказывание ребенком истории включались фрагменты диалога ребенка и взрослого-экспериментатора. Текстовый материал составил 25 устных историй с интерактивным компонентом; по возрастным группам: младшая группа (дети от 3 л. 3 мес. - до 4 л. 6 мес.) - 9 историй; средняя группа (4 л. 5 мес. - 5 л. 7 мес.) 11 историй; старшая и подготовительная группы (5 л. 5 мес. - 6 л. 11 мес.) - 5 историй.

Анализ текстового материала включал следующие задачи: а) выделить в нарративном материале регулярные последовательности высказываний в диалогическом взаимодействии ребенка и взрослого; б) определить функциональное назначение высказываний взрослого в ходе рассказывания и развертывания нарратива ребенком, т.е. определить нарративную задачу высказываний взрослого. В основе предпринятого анализа повествовательного материала лежит методика, предложенная Н. Хаузендорф и Ю. Кастхофф (Quasthoff, 1997: 51-83; Hausendorf \& 
Интерактивный компонент в устных нарративах детей-дошкольников...

Quasthoff, 1992: 241-260) применительно к конверсационному нарративу, который возникает в ходе рассказывания ребенком истории и является результатом совместных усилий ребенкарассказчика и взрослого.

\section{Результаты и дискуссии}

Далее представлена краткая характеристика рассказанных детьми историй и высказываний взрослого, включенных в нарративный процесс.

В младшей группе (дети от 3 л. 3 мес. - до 4 л. 6 мес.) зафиксированы 9 историй с интерактивным компонентом. В этот возрастной период для большинства детских историй характерна неупорядоченная форма истории в виде «скопления» высказываний, т.е. целостная осмысленная история у детей не возникает (Сигал, Бакалова, Пушина \& Юрьева, 2013). По каждому эпизоду ребенок сообщает о действиях участников истории, прибегая к простым высказываниям, отражающим ситуативное восприятие фрагментов истории через пропозициональную структуру «субъект - действие», «субъект - действие - объект действия». В бутылку залез, там лягушка / Упал он. Часто ребенок вступал в рассказывание только после общего вопроса взрослого о том, что нарисовано в книжке. Что здесь нарисовано? В ответ ребенок начинал историю с выделения и обозначения основных участников конкретного эпизода истории: щенок, лягушка, мальчик. Затем история предстает в виде несфокусированной нарративной цепи, состоящей из сообщений, фиксирующих визуально наблюдаемые действия участников истории. Вероника С., 4 г. 3 мес.: Мальчик в кровати / В окно выглядывает / $A$ здесь лягушка.

Существенной характеристикой историй детей $3-4$ лет является включение в ход рассказывания обращценных к взрослому вопросов ребенка, которые сопровождают осмысление ребенком эпизодов истории и относятся к восприятию и пониманию содержания эпизодов, действий участников истории, к определению предметов и их признаков. Маша П., 3 г. 11 мес.: Голый / Он че (что) спит? Нагулялся / А это че (что) банка? Стеклянная? / А это кто такой? 
Interactive Component in Oral Narratives of Preschool Children...

Отмечены вопросы взрослого, имеющие цель обратить внимание ребенка на действия участников истории: (взр. - далее (1) Что они делают? / (реб. - далее (2) Спят. (1) A лягушка? / (2) А лягушка вылезает. (1) Что делает олень? / (2) Мальчика несет олень.

Речевая активность взрослого в рассказывании истории детьми трех - четырех лет минимальна и составила не более $1 \%$ от общего количества высказываний ребенка в ходе рассказывания, которые в среднем составили около 20-24 высказываний.

В средней группе (дети от 4 л. 5 мес. - 5 л. 7 мес.) зафиксировано 11 историй с встроенным интерактивным компонентом. В целом процесс нарративизации у детей среднего и младшего дошкольного возраста не отличался. Происходящие события представляются детьми с помощью указания на участников истории (основных и возникающих далее в эпизодах) и их действий. Дети прибегали к перечислению одновременно происходящих действий участников истории, т.е. ребенок рассказывал историю с опорой на иллюстрации по каждому эпизоду путем перечисления «фактов-действий». Развитие пропозиции проходит по принципу уточнения характеристик участников и их действий. (2) Bom собачку взял и пошел / а потом он на лося залез / Мальчик на дерево залез и собака.

Вопросы ребенка, обращенные к взрослому, представляют собой общие локальные вопросы, относящиеся к отдельным эпизодам с целью ориентации в происходящей ситуации, а также означивания воспринимаемой ситуации и предметов. Например: A это что? Как это называется? А потом он взял ... это что? / А это чтмо? Бревно?

Активность взрослого в рассказывании истории детьми средней возрастной группы выросла и составила около $4 \%$ от общего количества высказываний ребенка (приблизительно 3035 высказываний). Рост (хотя и не столь значительный) речевой активности взрослого, на наш взгляд, можно объяснить стремлением взрослого подвести ребенка к области его потенциальных возможностей и перевести нарратив от последовательного описания каждого эпизода и перечисления участников и их действий к анализу ситуации и выделению взаимосвязи в действиях основных героев истории. Участие взрослого реализуется в следующих речевых действиях: 
Интерактивный компонент в устных нарративах детей-дошкольников...

- побуждение ребенка к нарративу путем выделения основного действующего лица истории и указания на важность происходящих событий с использованием конкретных вербальных средств: Танечка, теперь расскажи, что случилось с мальчиком?; Что произошло с мальчиком?;

- вопросы взрослого, а) относящиеся к изображению эпизодов истории, выделению участников истории, их действий; б) направленные на установление структуры события, выделение важных компонентов происходящих событий, на анализ и интеграцию информации: Кто в банке? A здесь что? Мальчик спит? А лягушка? Что делает собачка? А потом? Что случилось потом, посмотри?

Следует отметить, что в структуре вопросов взрослого, однако, преобладают вопросы, относящиеся к выделению участников истории и их действий. Это кто? Что он делает? Поэтому ответные нарративные структуры ребенка по следующим эпизодам строятся по принципу «субъект - действие», «субъект - действие объект действия». (2) Мальчик забрался на гору. Мальчик залез на дерево;

- предложение взрослым своего осмысления событийного ряда для ребенка и смыслового ядра истории, отмеченное в единичных рассказах. (1) Может быть, они ищут лягушку? / Ну, если у него убежала лягушка, может быть, он лягушку ищет?;

- означивание и пояснение незнакомых ребенку предметов. (1) Это осиное гнездо, здесь живут осы.

В этой возрастной группе также обнаружены случаи совместного ребенком и взрослым построения многокомпонентного расчлененного повествовательного высказывания. (2) Собачка заглянула вот, где лягушка сидит / (1) в баночку; (1) Собачка в банку / (2) залезла.

В старшей и подготовительной группах (5 л. 5 мес. 6 л. 11 мес.) зафиксированы всего 5 историй с интерактивным компонентом, поскольку дети этих возрастных групп в основном самостоятельно рассказывали историю (38 историй без участия взрослого), а взрослый вступал в процесс рассказывания, когда он считал, что ребенок испытывает затруднения в осмыслении истории и вербальном воплощении эпизодного ряда в целостный рассказ. Это можно объяснить тем, что в этот период в детских историях, 
Interactive Component in Oral Narratives of Preschool Children...

как нами отмечалось ранее, наблюдается осмысление ребенком целостности сюжета, возникновение смыслового ядра истории, сфокусированности рассказа и его вербального оформления в связную нарративную цепь с использованием бессоюзной и сочинительной связи. Для многих историй характерно развертывание темы по линии описания действий участников и их наглядных результатов (Сигал, Бакалова, Пушина \& Юрьева, 2013: 123-127).

Активность взрослого в рассказывании истории детьми 5-7 лет составила около 0,5\% от общего количества высказываний ребенка в нарративе (30-40 высказываний) и представлена в следующих регулярных речевых действиях:

- обозначение темы истории. Катя, mbl посмотрела интересную книжку, а сейчас расскажи историю про мальчика, собачку и лягуику;

- локальные вопросы, направленные выделение основных участников истории в отдельных эпизодах. Расскажи, что здесь нарисовано?;

- локальные вопросы взрослого о действиях и результатах действий участников истории, относящиеся к отдельным эпизодам. (2) Расскажси, что делает мальчик. Что с ним случилось? / (1) Мальчик падает, а олень лежит;

- вопросы, направленные на развитие сюжета истории. (2) И что было потом? / (1) Потом пошли они и кричам / Собачка потом от пчел ушла;

- коррекция взрослым лексических единиц, не адекватно используемых ребенком. (1) Мальчик зашел в дупло / (2) Посмотри, он заглянул в дупло.

Результаты анализа показывают, что, хотя условием проведения эксперимента было отстраненное участие взрослого, в ситуации рассказывания истории ребенком дошкольного возраста заметно действие интерактивного фактора: взрослые участники вступали в диалог с ребенком-рассказчиком и прибегали к различным приемам интенсификации когнитивно-дискурсивной деятельности ребенка, которые подталкивали его к рассказу истории. Использование взрослым вербальных форм воздействия в ходе рассказывания истории детьми, вслед за рядом исследователей, можно проинтерпретировать как необходимые средства поддержки или «скэффолдинг» (Bruner, 1985; Bamberg, 1997). 


\section{Выводы}

Результаты анализа свидетельствуют, что «поддерживающие» действия взрослого обращены к процессам, происходящим в когнитивной сфере ребенка, которые направлены на структурацию отдельных эпизодов истории, выделение участников, действий, результатов действий, «оречевление» событийных эпизодов и формирование многокомпонентного сообщения. Взрослый практически на каждой возрастной ступени в той или иной степени ориентирован на восприятие и осмысление ребенком эпизодов истории, т.е. на формирование у ребенка ментального представления о структурно-событийном ряде истории.

Проведенный анализ позволил выдвинуть гипотезу для следующего исследовательского этапа и следующего эксперимента с детьми 3-7 лет, но с активной позицией взрослого в повествовательной ситуации. По гипотезе, сама природа устного рассказа как многогранного феномена дискурсивной деятельности человека в речевом онтогенезе выводит на поверхность внутренние механизмы нарративизации, имеющие диалогическую основу в виде диалогических структур, потенциально заложенных в нарратив и необходимых для его порождения. Предлагаемая гипотеза представляет собой попытку подойти к трудному вопросу в теории нарративного развития, который относится к «латентным» когнитивно-дискурсивным механизмам, обеспечивающим порождение нарратива на смысловом этапе формирования нарративного дискурса в речи ребенка. Описанный материал служит иллюстрацией лингводидактических приемов и дискурсивных «опор» при обучении детей дошкольного и предшкольного возраста связной монологической речи.

\section{Литература}

Барт Р. Введение в структурный анализ повествовательных текстов. Франиузская семиотика : От структурализма $\kappa$ постструктурализму. Москва : Прогресс, 2000. С. 196-238.

Выготский Л.С. История развития высших психических функций. Собрание сочинений. Проблемы развития психики. Москва : Педагогика, 1983. T. III. 365 c. 
Interactive Component in Oral Narratives of Preschool Children...

Лепская Н.И. Язык ребенка. Онтогенез речевой коммуникации. Москва : МГУ, 1997. $151 \mathrm{c}$.

Лидерс А.Г., Фролов Ю.И. Метод планомерного формирования в истории советской психологии. Вестник МГУ. Серия: Психология. 1991. № 1. C. $49-58$.

Протасова Е.Ю. Развитие семантики высказывания в детской речи (психолингвистический анализ) : автореф. дисс. ... канд. филол. наук : 10.02.19. Москва : ИЯ АН СССР, 1987. 25 с.

Седов К.Ф. Становление дискурсивного мышления языковой личности. Саратов : Изд-во Саратовского университета, 1999. 180 с.

Седов К.Ф. Дискурс и личность. Москва : Лабиринт, 2004. 317 с.

Сигал К.Я., Юрьева Н.М. Метод эксперимента и его применение в речевых исследованиях. Москва : ИЯЗ РАН; ИД «Ключ-С», 2009. 236 с.

Сигал К.Я., Бакалова 3.Н., Пушина Н.И., Юрьева Н.М. Очерки по синтаксису связной речи. Москва : Ключ-С, 2013. 142 с.

Юрьева Н.М. Когнитивный подход в исследованиях устного нарратива в онтогенезе речи. Вестник Самарского Университета. История, педагогика, филология. 2016а. № 3(2). С. 24-27.

Юрьева Н.М. Механизмы устного нарратива в детской речи: когнитивный подход. Вопросы психолингвистики. 2016b. № 3(29). С. 285-298.

Юрьева Н.М. Интерактивный подход в изучении становления нарратива в онтогенезе речи. Филологические науки. Вопросы теории и практики. 2017. Часть 2. № 12(78). С. 178-181.

Юрьева Н.М. Интерактивный компонент в механизме порождения нарратива детьми. Вопросы психолингвистики. 2018. № 1(35). С. 115-123.

Berman, R.A., \& Slobin, D.I. (1994). Different ways of relating events in narrative: a crosslinguistic developmental study. Hillsdale, NJ: L. Erlbaum.

Bruner, J. (1985). The role of interaction formats in language acquisition. J.P. Forgas (Ed.), Language and social situations, (pp. 31-46). New York : Springer.

Bamberg, M. (Eds.). (1997). Narrative development : six approaches. New York London : Routledge.

Hausendorf, H., \& Quasthoff, U.M. (1992). Patterns of adult - child interaction as a mechanism of discourse acquisition. Journal of pragmatics, 17, 241-260. https:// doi.org/10.1016/0378-2166(92)90004-U

Mayer, M. (1969). Frog, where are you? New York: Dial Books for Young Readres.

Quasthoff, U.M. (1997). An interactive approach to narrative development. In M. Bamberg (Eds.), Narrative development: six approaches. (pp. 51-83). New York - London : Routledge.

Stein, N.L., \& Albro, E.R. (1997). Building complexity and coherence: children's use of goal-structured knowledge in telling stories. In M. Bamberg (Eds.), Narrative development: six approaches. (pp. 5-44). New York - London : Routledge.

Trabasso, T., Stein, N.L., \& Rodkin, P. (1992). Knowledge of goals and plans in the on-line narration of events. Cognitive development, 7, 133-170. https://doi. org/10.1016/0885-2014(92)90009-G 


\section{References}

Bart, R. (2000). Vvedenie v strukturnyj analiz povestvovatelnyx tekstov [Introduction to the structural analysis of narratives]. Franczuzskaya semiotika: Ot strukturalizma k post-strukturalizmu - Semiotic French: from structuralism to post-structuralism, (pp. 196-238). Moscow : Progress [in Russian].

Vygotskij, L.S. (1983). Istoriya razvitiya vysshix psixicheskix funkcij [The development of higher mental fuctions]. Sobranie sochinenij-Collected works. Moscow : Pedagogika [in Russian].

Lepskaya, N.I. (1997). Yazyk rebenka. Ontogenez rechevoy kommunikacii [Child language. Ontogenesis of speech communication]. Moscow : MGU im. M.V. Lomonosova [in Russian].

Liders, A.G., \& Frolov, Yu.I. (1991). Metod planomernogo formirovaniya v istorii sovetskoj psixologii [Method of planed formation in the history of Soviet psychology]. Vestnik MGU. Ser. Psyxologiya - Journal MGU. Ser. Psychology, 1, 49-58 [in Russian].

Protasova, E.Yu. (1987). Razvitie semantiki vyskazyvaniya v detskoj rechi (psixolingvisticheskij analiz) [Development of semantic of sentences in child language (analysis psycholinguistics)]. Extended abstract of candidate's thesis. Moscow : IYZ RAN [in Russian].

Sedov, K.F. (1999). Stanovlenie diskursivnogo myshleniya yazykovoj lichnosti [Evolution of discursive thinking of language personality]. Saratov : Saratov University [in Russian].

Sedov, K.F. (2004). Diskurs $i$ lichnost. Evolutsiya communicativnoy competentsii [Discours and personality. Evolution of communicative competence]. Moscow : Labirint [in Russian].

Sigal, K.Ya., \& Yurieva, N.M. (2009). Metod eksperimenta $i$ ego primenenie $v$ rechevyx issledovaniyax [Method of experiment and its application in the study of speech]. Moscow : «Klyuch-S» [in Russian].

Sigal, K.Ya., Bakalova, Z.N., Pushina, N.I., \& Yurieva, N.M. (2013). Ocherki po sintaksisu svyaznoj rechi [Essayson syntax of connected speech]. Moscow : «Klyuch-S» [in Russian].

Yurieva, N.M. (2016a). Kognitivnyj podxod $\mathrm{v}$ issledovaniyax ustnogo narrativa $\mathrm{v}$ ontogeneze rechi [The cognitive approach in study of oral narrative in child language]. Vestnik Samarskogo Universiteta. Istoriya, pedagogika, filologiya Journal University of Samara. History, Pedagogic, Philology, 3(2), 24-27 [in Russian].

Yurieva, N.M. (2016b). Mexanizmy ustnogo narrativa v detskoj rechi: kognitivnyj podxod [The mechanisms of oral narrative in child language: cognitive approach]. Voprosy psiholingvistiki - Questions of Psycolinguistics, 3(29), 285298 [in Russian].

Yurieva, N.M. (2017). Interaktivnyj podxod v izuchenii stanovleniya narrativa v ontogeneze rechi [Interactive approach to studying narrative formation in speech ontogenesis]. Filologicheskie nauki. Voprosy teorii $i$ praktiki - Philological Sciences. Issues of theory and practice, 12(78), 178-181 [in Russian].

Yurieva, N.M. (2018). Interaktivnyj component $\mathrm{v}$ mehanisme porozhdeniya narrative det'mi [Interactive component in generation of narrative by children]. Voprosy psiholingvistiki - Questions of Psycolinguistics, 1(35), 115- 123 [in Russian]. 
Berman, R.A., \& Slobin, D.I. (1994). Different ways of relating events in narrative: a crosslinguistic developmental study. Hillsdale, NJ: L. Erlbaum.

Bruner, J. (1985). The role of interaction formats in language acquisition. J.P. Forgas (Ed.), Language and social situations, (pp. 31-46). New York : Springer.

Bamberg, M. (Eds.). (1997). Narrative development : six approaches. New York London : Routledge.

Hausendorf, H., \& Quasthoff, U.M. (1992). Patterns of adult - child interaction as a mechanism of discourse acquisition. Journal of pragmatics, 17, 241-260. https:// doi.org/10.1016/0378-2166(92)90004-U

Mayer, M. (1969). Frog, where are you? New York: Dial Books for Young Readres.

Quasthoff, U.M. (1997). An interactive approach to narrative development. In M. Bamberg (Eds.), Narrative development: six approaches. (pp. 51-83). New York - London : Routledge.

Stein, N.L., \& Albro, E.R. (1997). Building complexity and coherence: children's use of goal-structured knowledge in telling stories. In M. Bamberg (Eds.), Narrative development: six approaches. (pp. 5-44). New York - London : Routledge.

Trabasso, T., Stein, N.L., \& Rodkin, P. (1992). Knowledge of goals and plans in the on-line narration of events. Cognitive development, 7, 133-170. https://doi. org/10.1016/0885-2014(92)90009-G

\section{АННОТАЦИЯ}

В статье представлена попытка разработки гипотезы экспериментального исследования, посвященного изучению интерактивного компонента в устных нарративах детей дошкольного возраста. Для психолингвистики важно приблизиться к пониманию сущности нарративных прочессов, имеющих в онтогенезе свою специфику, состоящую в том, что в порождение нарратива ребенком вовлечен интерактивный компонент в виде диалога ребенка и взрослого. Методология, цель и задачи исследования определяются экспериментально-генетическим методом (Л.С. Выготский) и его основными требованиями различения "анализа вещи и анализа процесса» и генетического восстановления всех моментов развития изучаемого процесса. Следование этим требованиям состоит в том, чтобы проследить становление нарратива в динамике и особенностях его формирования в разные периоды развития ребенка, обращая внимание на частотные фракты и на факты, выходящие за границы "узкого» феномена - нарративного текста.

Для обоснования гипотезы использован повествовательный материал ранее проведенного эксперимента с детьми трех - семи лет по рассказыванию истории с пассивной формой участия взрослого, не подвергавшийся анализу из-за включения взрослого в повествовательный прочесс. Анализ устных историй с интерактивным компонентом включал следующие задачи: а) выделить регулярные последовательности высказываний в диалогическом взаимодействии ребенка и взрослого; б) определить фрункциональное назначение высказываний взрослого в ходе рассказывания ребенком истории.

Полученные результаты свидетельствуют, что взрослый практически на каждой возрастной ступени ориентирован на восприятие и осмысление 
Интерактивный компонент в устных нарративах детей-дошкольников...

ребенком эпизодов истории, т.е. на формирование у него ментального представления о структурно-событийном ряде истории. Данные анализа позволили выдвинуть гипотезу для следующего исследовательского этапа. По гипотезе, в онтогенезе речи сама природа устного рассказа как френомена дискурсивной деятельности человека выводит на поверхность внутренние механизмы нарративизации, имеющие диалогическую основу.

Ключевые слова: устный нарратив, интерактивный компонент, генезис устного нарратива, диалогическая основа.

Юр'єва Надія. Інтерактивний компонент в усних наративах дітейдошкільників: до постановки гіпотези

\section{АНОТАЦІЯ}

у статті представлена гіпотеза експериментального дослідження, присвяченого вивченню інтерактивного компонента в усних наративах дітей дошкільного віку. Для психолінгвістики важливо наблизитися до розуміння сутності наративних процесів, що мають в онтогенезі свою специфіку, яка полягає в тому, що в процес породження наративу дитиною залучений інтерактивний компонент у вигляді діалогу дитини та дорослого. Методологія, мета і завдання дослідження визначаються експериментальногенетичним методом (Л.С. Виготський), його основними вимогами розрізнення "аналізу речі і аналізу процесу" та генетичного відновлення всіх аспектів розвитку досліджуваного процесу. Дотримання цих вимог полягає в тому, щоб простежити становлення наративу в динаміці й особливості його формування в різні періоди розвитку дитини, звертаючи увагу на частотні факти і на факти, що виходять за межі «вузького» феномена - наративного тексту.

Для обгрунтування гіпотези використано оповідний матеріал раніше проведеного експерименту з дітьми трьох - семи років з розповіданням розповідається історії при пасивній формі участі дорослого, що не піддавався аналізу через включення дорослого в розповідний процес. Аналіз усних історій з інтерактивним компонентом включав наступні завдання: а) виділити регулярні послідовності висловлювань в діалогічній взаємодії дитини $і$ дорослого; б) визначити функціональне призначення висловлювань дорослого в ході розповідання дитиною історії.

Отримані результати свідчать про те, що дорослий практично на кожному віковому етапі дошкільників орієнтований на сприйняття і осмислення дитиною епізодів історії, тобто на формування у дитини ментального уявлення про структурно-подієвий ряд історії. Дані аналізу дозволили висунути гіпотезу для наступного дослідницького етапу. Відповідно до гіпотези, в онтогенезі мови сама природа усного оповідання як френомена дискурсивної діяльності людини виводить назовні внутрішні механізми наративізації, які мають діалогічну основу.

Ключові слова: усний наратив, інтерактивний компонент, генезис усного наративу, діалогічна основа. 